\title{
Incidence and survival of retinoblastoma in the Netherlands: a register based study 1862-1995
}

Department of Ophthalmology, Vrije Universiteit, Amsterdam, Netherlands A C Moll $S$ M Imhof

K E W P Tan

Department of

Epidemiology and

Biostatistics, Vrije

Universiteit,

Amsterdam,

Netherlands

D J Kuik

L M Bouter

P D Bezemer

Department of

Functional

Morphology, Utrecht

University,

Netherlands

W Den Otter

J W Koten

Department of Human Genetics, Vrije

Universiteit,

Amsterdam,

Netherlands

B P Kuyt

Correspondence to: A C Moll, MD, Department of Ophthalmology, Free University Hospital, De Boelelaan 1117, $1081 \mathrm{HV}$ Amsterdam, Netherlands.

Accepted for publication 11 March 1997

Annette C Moll, D Joop Kuik, Lex M Bouter, Willem Den Otter, P Dick Bezemer, Jan Willem Koten, Saskia M Imhof, Bertus P Kuyt, Karel E W P Tan

\begin{abstract}
Aim-The aim of this study was to determine the (time trends in) incidence and survival of hereditary (familial and sporadic) and non-hereditary retinoblastoma for male and female patients born in the Netherlands between 1862 and 1995. Method-The national retinoblastoma register was updated and now consists of 955 patients. The missing dates of death were obtained from the municipal registers and the Central Bureau of Genealogy in The Hague. Mortality was compared with the Dutch vital statistics.

Results-From 1862 to 1995 no significant differences in incidence for retinoblastoma were found in the hereditary subgroups. Further, no significant differences between males and females were found, both overall and in the hereditary subgroups. The average incidence of retinoblastoma increased untill 1944, probably due to incompleteness of the register, and stabilised after 1945 (1 per 17000 live births). From 1900 to 1995 the standardised mortality ratio increased for hereditary retinoblastoma patients from 2.9 to 9.0 and decreased for non-hereditary retinoblastoma patients from 1.9 to 1.0 .

Conclusion-Although survival for retinoblastoma was significantly better after 1945 than before, in comparison with the Dutch population the mortality between 1900 and 1990 increased for the hereditary and decreased for the non-hereditary retinoblastoma patients.

(Br f Ophthalmol 1997;81:559-562)
\end{abstract}

Retinoblastoma is a rare paediatric eye tumour which occurs in a hereditary and a nonhereditary form. All bilateral (familial or sporadic) cases and the familial unilateral cases can be considered to be hereditary $(30 \%-40 \%$ of the cases). ${ }^{1}$ In familial cases the patient inherits the retinoblastoma mutation from a carrier parent and in sporadic bilateral cases from a healthy parent in whom a new germinal mutation has occurred.

The incidence of retinoblastoma reported in the literature ranges from 1:10 000 in South Africa to 1:34 000 in the Netherlands (Table 1). ${ }^{1-21}$ These extreme values come from hospital populations and are based on very crude estimations and are therefore probably inaccurate. ${ }^{1}$ During the past years it has often been discussed whether there has been any change in the incidence of this malignant disease..$^{22}{ }^{23}$ The survival rate of retinoblastoma improved in the last century, ${ }^{24}$ mostly because of Wardrop's recommendation to enucleate a retinoblastoma eye..$^{25}$ As a consequence, hereditary retinoblastoma patients were able to have offspring and this presumably led to a gradual increase in the incidence of hereditary retinoblastoma in the population.

Furthermore, there is still a discussion in the literature regarding the sex predominance of retinoblastoma patients. Pendergrass and Davis $^{7}$ found no difference in the incidence of retinoblastoma between males and females. Naumova and Sapienza ${ }^{26}$ found a significant overrepresentation of males among bilateral sporadic cases.

$\mathrm{Neel}^{27}$ and Vogel $^{1}$ discussed a possible viral aetiology of retinoblastoma. A seasonal variation in births of children with non-hereditary retinoblastoma would suggest that the disease is possibly influenced by certain environmental agents such as viral infection.

The National Retinoblastoma Register of the Netherlands offers the unique opportunity to analyse the above mentioned controversies in the literature. Therefore, the purposes of this study were to determine for hereditary (sporadic and familial) and non-hereditary retinoblastoma patients: (1) the (time trends in) incidence, (2) the difference in incidence between males and females, (3) the difference in incidence between different months, (4) time trends in survival, (5) the difference in survival between male and female patients.

\section{Methods}

The National Retinoblastoma Register of the Netherlands ${ }^{28} 29$ was used in the updated version. ${ }^{30}$ It can be regarded as virtually complete for patients born from 1945 to date. ${ }^{17}$ We gathered the dates of birth and death of the 955 registered Dutch retinoblastoma patients born from 1862 to 1995 . If possible, missing dates of death of patients were obtained with the help of the municipal registers and the Central Bureau of Genealogy in The Hague.

Retinoblastoma was regarded to be hereditary if at least one of the following criteria was met: bilateral retinoblastoma, family history for retinoblastoma (then the parent would be carrier of the defect in the retinoblastoma gene), or a defect in the retinoblastoma gene was found in chromosomal/DNA analysis of the patient. Sporadic hereditary retinoblastoma patients are the first cases known in a family. Some sporadic unilateral retinoblastoma pa- 
Table 1 Incidence figures of retinoblastoma cited in the literature

\begin{tabular}{|c|c|c|c|c|}
\hline Population & $\begin{array}{l}\text { Time } \\
\text { period }\end{array}$ & $\begin{array}{l}\text { No of } \\
\text { cases }\end{array}$ & Incidence $^{*}$ & Reference \\
\hline \multicolumn{5}{|l|}{ Africa } \\
\hline Bantu, South Africa & $1955-75$ & 80 & $1: 10000$ & Freedman and Goldberg, $1976^{2}$ \\
\hline Malawi & 1975 & 20 & $1: 10000$ & BenEzra and Chirambo, $1976^{3}$ \\
\hline \multicolumn{5}{|l|}{ America } \\
\hline USA & 1969-71 & 59 & $1: 18000$ & Devesa, $1975^{4}$ \\
\hline Michigan, USA & ? & 49 & $1: 20000$ & Falls and Neel, $1951^{5}$ \\
\hline Ohio, USA & ? & 126 & $1: 24000$ & Macklin, $1961^{6}$ \\
\hline USA & $1974-6$ & 70 & $1: 18000$ & Pendergrass and Davis, $1980^{7}$ \\
\hline \multicolumn{5}{|r|}{ 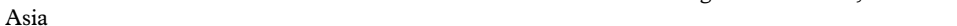 } \\
\hline Hokkaido, Japan & $1945-57$ & 69 & $1: 24000$ & Matsunaga and Ogyu, $1959^{8}$ \\
\hline Nagasaki, Japan & $1965-86$ & 34 & $1: 16000$ & Takano et al, $1991^{\circ}$ \\
\hline \multicolumn{5}{|l|}{ Australia, New Zealand } \\
\hline Australia & $1956-76$ & 80 & $1: 17000$ & O’Day et al, $1977^{10}$ \\
\hline New Zealand & $1948-77$ & 100 & $1: 18000$ & Suckling et al, $1982^{11}$ \\
\hline \multicolumn{5}{|l|}{ Europe } \\
\hline Denmark & $1928-57$ & 118 & $1: 19000$ & Bech and Jensen, $1961^{12}$ \\
\hline Finland & $1950-64$ & $?$ & $1: 16000$ & Tarkkanen and Tuovinen, $1971^{13}$ \\
\hline France & $1951-60$ & 295 & $1: 28000$ & Briard-Guillemot et al, $1974^{14}$ \\
\hline Germany & $1934-51$ & 48 & $1: 29000$ & Vogel, $1979^{1}$ \\
\hline Great Britain & $1962-80$ & 431 & $1: 23000$ & Sanders et al, $1988^{15}$ \\
\hline The Netherlands & $1927-9$ & $?$ & $1: 34000$ & Hemmes, $1931^{16}$ \\
\hline The Netherlands & $1945-70$ & 486 & $1: 16000$ & DerKinderen et al, $1990^{17}$ \\
\hline Northern Ireland & $1938-56$ & 23 & $1: 27000$ & Stevenson and Martin, $1957^{18}$ \\
\hline Norway & $1950-73$ & 75 & $1: 17000$ & Hørven, $1973^{19}$ \\
\hline Sweden & $1958-71$ & 88 & $1: 18000$ & Kock and Naeser, $1973^{20}$ \\
\hline \multicolumn{5}{|l|}{ Middle East } \\
\hline Riyadh, Saudi Arabia & $1982-6$ & 22 & $1: 12000$ & Al-Idrissi et al, $1991^{21}$ \\
\hline
\end{tabular}

${ }^{\star}$ Incidence in number of retinoblastoma patients per live births.

tients might be classified incorrectly as nonhereditary, since approximately $10 \%$ of the hereditary retinoblastoma patients are affected unilaterally. ${ }^{1}$

STATISTICAL ANALYSES

The total annual number of live births by sex in the Netherlands is available until $1994 .^{31}$ The cumulative incidences of the different retinoblastoma subgroups (sporadic hereditary, familial hereditary, and non-hereditary) were calculated in 5 year birth cohorts. The number of liveborn retinoblastoma patients was divided by the number of live births in the Netherlands in the same period (irrespective of the moment of diagnosis). Linear regression analyses were performed to detect a significant trend in incidence for the different retinoblastoma groups from 1862 to 1995 .

Difference in incidence between sexes was investigated by testing the percentage of males in the retinoblastoma group against percentages of males and females in the same birth cohort in the Dutch population, using the binominal distribution. Sex differences between the retinoblastoma subgroups were compared with the $\chi^{2}$ test for contingency tables.

Differences in incidence between months were investigated for each retinoblastoma subgroup, using a multinominal distribution, with the (relative) monthly birth frequencies of the Dutch population as variables.

The age at diagnosis was not always available for the patients born before 1945. Therefore, the survival curves are based on age since birth instead of in years after diagnosis. Survival was described with Kaplan-Meier curves, using the Mantel-Cox (log rank) test to determine differences in survival curves among the groups of interest.

The standardised mortality ratio (SMR) for the different retinoblastoma groups was calculated $^{32}$ in 10 year mortality groups. An
SMR of 1.25 for example means $25 \%$ 'extra mortality' in the retinoblastoma patients in comparison with the Dutch population. ${ }^{33}$ The Dutch mortality rates in age groups per calendar year of death were available from 1900 to date. ${ }^{34}$ Confidence intervals ( $95 \%$ CI) were calculated using the logarithm of the SMR. ${ }^{32}$ In order to detect a trend in the SMR from 1900 to 1995 regression analyses on the logarithm of the SMR were done. This project was approved by the medical ethics committee of the Free University Hospital, Amsterdam, the Netherlands.

\section{Results}

HEREDITY

Sex and heredity of the retinoblastoma patients are shown in Table 2. Forty nine of the 350 hereditary retinoblastoma patients $(14 \%)$ had the unilateral form; 320 of the 635 unilateral tumours were sited in the right eye and 296 in the left eye; in 19 unilateral cases the location of the tumour was unknown. The retinoblastoma subcohort 1945-94 has nearly the same composition as the total cohort (data not shown).

INCIDENCE BY SEX

In the period 1862-1995, no significant difference was found in incidence for retinoblastoma between males and females in the retinoblastoma subgroups (sporadic hereditary, familial hereditary, and non-hereditary). Furthermore, our investigation did not reveal any significant difference between the male/female ratio in various retinoblastoma subgroups and the Dutch population. Moreover, in the subcohort 1945-94 no significant difference in male/ female ratio was found between the different retinoblastoma subgroups, or compared with the Dutch population (data no shown).

TIME TRENDS IN INCIDENCE

Figure 1 shows the number of retinoblastoma patients per 100000 life births in 5 year cohorts in the Netherlands. The incidence of retinoblastoma increased significantly from 1862 to 1945. After 1945 there was no evidence of an increase in the total incidence of retinoblastoma, nor was there any significant change in incidence in the retinoblastoma subgroups (sporadic hereditary, familial hereditary, and non-hereditary retinoblastoma; data not shown). The average incidence of retinoblastoma after 1945 was 1:17 000 (95\% CI; $1: 15$ 500-1:18 500) (5.8 per 100 000) live births (range $13000-25000$ ).

Table 2 Sex and heredity of patients in the National Retinoblastoma Register of the Netherlands from 1862 to 1995

\begin{tabular}{llll}
\hline Group & Male (\%) & Female (\%) & Total \\
\hline Non-hereditary & $318(54.3)$ & $268(45.7)$ & 586 \\
Sporadic hereditary & $130(52.2)$ & $119(47.8)$ & $249^{\star}$ \\
Familial hereditary & $47(46.5)$ & $54(53.5)$ & $101 \dagger$ \\
Unknown & 8 & 11 & 19 \\
Total & $503(52.7)$ & $452(47.3)$ & 955 \\
\hline
\end{tabular}

*Including 29 unilateral patients.

tIncluding 20 unilateral patients. 


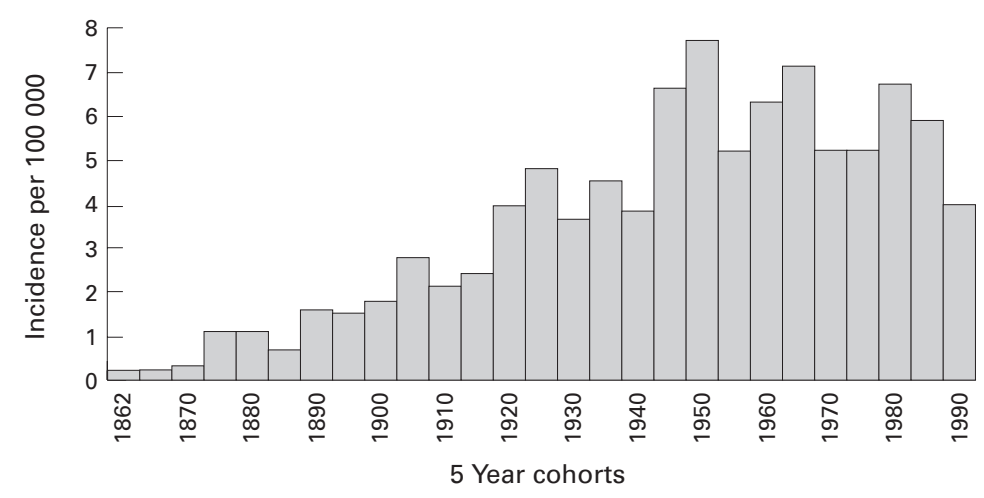

Figure 1 Incidence of retinoblastoma in the Netherlands in 5 year cohorts from 1862 to 1994. The incidence is expressed in number of retinoblastoma patients per 100000 live births in the Netherlands in the same period (irrespective of the moment of diagnosis).

Table 3 Cumulative survival for the subcohorts of retinoblastoma patients: $1945-94$

\begin{tabular}{llll}
\hline Group & No & $\begin{array}{l}\text { Survival }^{*} \\
\text { until age 5 }^{*}\end{array}$ & $\begin{array}{l}\text { Survival }^{*} \\
\text { until age 35 }^{*}\end{array}$ \\
\hline Non-hereditary & 395 & $91.8 \%$ & $88.5 \%$ \\
Hereditary & 242 & $87.2 \%$ & $72.0 \%$ \\
Sporadic hereditary & 164 & $87.4 \%$ & $74.1 \%$ \\
Familial hereditary & 78 & $86.8 \%$ & $67.3 \%$ \\
Female & 300 & $91.6 \%$ & $84.3 \%$ \\
Male & 337 & $88.7 \%$ & $80.3 \%$ \\
All & 637 & $90.1 \%$ & $82.2 \%$ \\
\hline
\end{tabular}

$\star$ Survival per number of liveborn retinoblastoma patients.

INCIDENCE PER MONTH

The distribution of the retinoblastoma subgroups does not show significant differences over the 12 months of the year in comparison with the Dutch population. There appears to be a slight, but not significant excess of retinoblastoma affected newborns from December to May (data not shown).

SURVIVAL

In all, 287 of the 955 patients born between 1862 and 1995 had died; 640 patients were still alive and 28 patients could not traced for follow up. Five hundred and thirty eight patients of the subcohort 1945-94 were still alive; 99 patients had died and eight patients could not be traced for follow up. Cumulative survival at 5 and 35 years of age for the different retinoblastoma subgroups is shown in Table 3 . There was a significant difference in cumulative survival between hereditary and non-hereditary retinoblastoma $(\mathrm{p}<0.005)$. The difference in survival between sporadic hereditary and familial hereditary survival was not significant. The difference in survival between male and female retinoblastoma patients was also not statistically significant.

The survival at 5 years $(p<0.01)$ and 35 years $(p<0.01)$ of age was significantly better for patients born after 1945 than for patients born before 1945. SMRs for the period 18981995 are given in Table 4. No trend in the SMR could be found for the total group of patients. However, for the hereditary patients the SMR increased significantly $(\mathrm{p}=0.007)$, while for the non-hereditary patients a significant decrease trend was found $(\mathrm{p}=0.017)$.
Table 4 Standardised mortality ratio (SMR) for retinoblastoma patients

\begin{tabular}{|c|c|c|c|}
\hline & All RB & Hereditary & Non-hereditary \\
\hline Cohort & $\begin{array}{l}S M R \\
(95 \% C I)\end{array}$ & $\begin{array}{l}S M R \\
(95 \% C I)\end{array}$ & $\begin{array}{l}S M R \\
(95 \% C I)\end{array}$ \\
\hline $1898-1907$ & $1.4(0.7-2.6)$ & - & $1.9(1.0-3.7)$ \\
\hline $1908-17$ & $2.7(1.7-4.3)$ & $2.9(1.1-7.4)$ & $2.7(1.6-4.8)$ \\
\hline $1918-27$ & $3.2(2.2-4.7)$ & $3.6(2.1-6.2)$ & $2.9(1.7-5.0)$ \\
\hline $1928-37$ & $3.3(2.2-4.9)$ & $4.5(2.5-8.2)$ & $2.4(1.4-4.3)$ \\
\hline $1939-47$ & $2.2(1.4-3.3)$ & $2.6(1.3-5.0)$ & $1.8(1.0-3.2)$ \\
\hline $1948-57$ & $2.6(1.8-3.7)$ & $3.3(1.9-6.0)$ & $2.1(1.3-3.5)$ \\
\hline $1958-67$ & $3.0(2.1-4.3)$ & $5.0(3.0-8.0)$ & $2.1(1.3-3.5)$ \\
\hline $1968-77$ & $2.6(1.8-3.7)$ & $5.5(3.4-8.9)$ & $1.6(1.0-2.8)$ \\
\hline $1978-87$ & $2.8(2.0-3.9)$ & $5.7(3.6-9.0)$ & $1.7(1.0-2.9)$ \\
\hline $1988-95$ & $3.1(2.1-4.7)$ & $9.0(5.5-14.4)$ & $1.0(0.5-2.3)$ \\
\hline
\end{tabular}

$\mathrm{RB}=$ retinoblastoma

$95 \% \mathrm{CI}=95 \%$ confidence interval.

\section{Discussion}

HEREDITY

The percentage of hereditary and nonhereditary retinoblastoma $(61.4 \%$ and $36.6 \%$, respectively) was similar to the percentage published by Vogel. ${ }^{1}$ In addition, he found that $10 \%-12 \%$ of the unilateral sporadic cases were in fact new germline mutants; we found a nearly similar percentage of 14.0 .

INCIDENCE BY SEX

Several studies showed no sex differences in the incidence of retinoblastoma. ${ }^{5135} \mathrm{Nau}-$ mova and Sapienza ${ }^{26}$ made an extensive compilation of the literature regarding sex and laterality of proved sporadic cases and found a significant overrepresentation of males among bilateral sporadic cases. For unilateral retinoblastoma they could not find such a difference. We could not confirm their first mentioned findings.

TIME TRENDS IN INCIDENCE

As discussed by Vogel $^{1}$ studies covering more recent periods tend to give higher values of incidence of retinoblastoma. The most obvious explanation is a more complete ascertainment in the more recent studies. This can also explain the increasing incidence we found in the period 1862-1944. It seems that especially in the period 1862-1900 the tumour was often not recognised and/or registered. Vogel $^{1}$ did not exclude that there has been a true increase in incidence of retinoblastoma. However, the incidence in the period 1945-94 did not change significantly in our study. Probably, in this period the tumour was diagnosed correctly and the register was really complete.

\section{INCIDENCE PER MONTH}

Earlier reports ${ }^{151136}$ failed to show clustering of sporadic hereditary or non-hereditary retinoblastoma in specific months. Our data revealed fluctuations to some extent by month of birth, but this was not statistically significant.

SURVIVAL

In 1809 , Wardrop ${ }^{25}$ advocated enucleation of a retinoblastoma containing eye as a lifesaving measure. It is the general opinion that early enucleation contributed to a better survival. ${ }^{24}$ However, new treatment modalities (irradia- 
tion or coagulation) were developed to save life and preserve vision. Bishop and $\mathrm{Madsen}^{37}$ reported an increase in the survival of retinoblastoma of $5 \%$ in 1869 to $81 \%$ in 1967 . This study also showed an increasing survival. It should be stressed also that from 1900 the survival in the general population ${ }^{34}$ increased dramatically. Taking this into account, it is clear from the trend analysis of the SMR that survival for the hereditary group could not follow the improvement in the general population.

The risk of death is significantly higher for a retinoblastoma patient than for an average member of the Dutch population, as all SMRs are larger than 1 . In other words, the improved diagnostic technique and improved retinoblastoma treatment did not result in the same length of survival for the general Dutch population and patients with hereditary retinoblastoma, in particular. Mortality increased significantly compared with the mortality of the general population $(p=0.007)$. In contrast, there was a significantly decreased 'extra mortality' of the non-hereditary patients $(p=0.017)$. These findings can probably be explained by the hereditary retinoblastoma gene disorder. Hereditary retinoblastoma patients are vulnerable for second primary tumours and pineoblastomas. ${ }^{30}$ Furthermore, treatment of hereditary (bilateral) retinoblastoma patients is more often irradiation than that of non-hereditary patients, because nonhereditary patients are mostly enucleated. DerKinderen et $a l^{38}$ have shown that irradiation therapy is an extra risk factor for second primary tumours in hereditary retinoblastoma patients. This will lead to death in many cases. On the other hand no second primary tumours were induced by irradiation of non-hereditary retinoblastoma patients ${ }^{39}$; consequently, nonhereditary retinoblastoma patients will be cured and survival will be improved.

This study was supported by grants from the Haak-BastiaanseKuneman-stichting.

1 Vogel F. Genetics of retinoblastoma. Hum Genet 1979;52:154.

2 Freedman J, Goldberg L. Incidence of retinoblastoma in the Bantu of South Africa. Br f Ophthalmol 1976;60:655-66.

3 BenEzra D, Chirambo MC. Incidence of retinoblastoma in Malawi. F Pediatr Ophthalmol 1976;13:340-3.

4 Devesa SS, The incidence of retinoblastoma. Am f Ophthalmol 1975;80:263-5.

mol 1975;80:263-5.
5 Falls HF, Neel JV. Genetics of retinoblastoma. Arch Ophthalmol 1951;46:367-89.

6 Macklin MT. A study of retinoblastoma in Ohio. Am f Hum Macklin MT. A study

7 Pendergrass TW, Davis S. Incidence of retinoblastoma in the United States. Arch Ophthalmol 1980;98:1204-10.

8 Matsunaga E, Ogyu. Genetic study of retinoblastoma in a Japanese population. Fpn F Human Genet 1959;4:156.
9 Takano J, Akiyama K, Imamura N, Sakuma M, Amemiya. Incidence of retinoblastoma in Nagasaki Prefecture, Japan. Ophthalmic Paediatr Genet 1991;12:139-44.

10 O'Day J, Billson FA, Hoyt GS. Retinoblastoma in Victoria. Med F A Ast 1977;2:428-32.

11 Suckling RD, Fitzgerald PH, Stewart J, Wells E. The incidence and epidemiology of retinoblastoma in New Zealand: a 30-year survey. Br f Cancer 1982;46:729-36.

12 Bech K, Jensen OA. Bilateral retinoblastma in Denmark, 1928-1957. Acta Ophthalmol 1961;39:561-8.

13 Tarkkanen A, Tuovinen E. Retinoblastoma in Finland 1912-1964. Acta Ophthalmol 1971;492:93-300.

14 Briard-Guillemot ML, Bonaïti-Pellie C, Feingold J, Frezal J. Etude génétique du retinoblastoma. Humangenetik 1974; 24:271-84.

15 Sanders BM, Draper GJ, Kingston JE. Retinoblastoma in Great Britain 1969-80: incidence, treatment, and survival Br f Ophthalmol 1988;72:576-83.

16 Hemmes GD. Untersuchungen nach dem Vorkommen von Glioma retinae bei Verwandten von mit dieser Krankheit Behafteten. Klin Monatsbl Augenheilkd 1931;86:331-5.

17 DerKinderen DJ, Koten JW, Tan KEWP, Beemer FA, Van Romunde LKJ, Den Otter W. Parental age in sporadic hereditary retinoblastoma. Am f Ophthalmol 1990;110:

18 Stevenson AC, Martin VAF. Retinoblastoma, occurence of the condition in Northern Ireland. Brit $\mathcal{F}$ Prev Soc Med 1957;11:29-35.

19 Horven I. Retinoblastoma in Norway. Acta Ophthalmol 1973;51:103-9.

20 Kock E, Naeser P. Retinoblastoma in Sweden 1958-1971. Acta Ophthalmol 1973;57:344-50.

21 Al-Idrissi I, Al-Kaff A, Senft SH. Cumulative incidence of retinoblastoma in Riyadh, Saudi Arabia. Ophthalmic Paediatr Genet 1991;13:9-12.

22 Muir KR, Smith H, Parkes SE, Willshaw H, Harry J, Mann $\mathrm{JR}$, Stevens MC. Increasing incidence of retinoblastoma? Arch Dis Childh 1990;65:915.

23 Parkes SE, Amoaku WM, Muir KR, Willshaw HE, Mann JR. Thirty years of retinoblastoma (1960-1989) changing patterns of incidence. Paediatr Perinat Epidemiol 1994;8: patterns

24 Shields JA, Shields CL. Retinoblastoma. In: Intraocular tumors, a text and atlas. Philadelphia: WB Saunders, 1992:305-91.

25 Wardrop J. Observations on the fungus Haematodes. Edinburgh: Constable, 1809

26 Naumova A, Sapienza C. The genetics of retinoblastoma, revisited. Am f Hum Genet 1994;54:264-73.

27 Neel JV. Mutations in the human population. Methodol Human Genet 1962;203-24.

28 Schappert-Kimmijser J, Hemmes GD, Nijland R. The heredity of retinoblastoma. Ophthalmologica 1966;151:197213.

29 DerKinderen DJ. A new concept of oncogenesis with an evaluation in retinoblastoma. Thesis, Utrecht, 1987

30 Moll AC, Imhof SM, Koten JW, Bezemer PD, Kuik DJ, Bouter LM, et al. Second primary tumors in patients with hereditary retinoblastoma: a registered-based follow-up study 1945-1994. Int F Cancer 1996;67:515-9.

31 Centraal Bureau voor de Statistiek. Statistiek van de loop der bevolking. The Hague, 1936-1994.

32 Rothman KJ. Modern epidemiology.Boston: Little, Brown, 1986:232.

33 Bouter LM, Van Dongen MCJM. Epidemiologisch onderzoek. Houten/Antwerp: Bohn Stafleu Van Loghum, 1991:37.

34 Centraal Bureau voor de Statistiek. Sterftecijfers 1990-1994. The Hague.

35 Jensen RD, Miller RW. Retinoblastoma: epidemiological characteristics. N Engl f Med 1971;285:307-11.

36 Matsunaga E, Minoda K, Sasaki MS. Parental age and seasonal variation in the births of children with sporadic retinoblastoma: a mutation-epidemiologic study. Hum Genet 1990;84:155-8.

37 Bishop JO, Madsen EC. Retinoblastoma: Review of current status. Surv Ophthalmol 1975;19:342-66.

38 DerKinderen DJ, Koten JW, Nagelkerke NJD, Tan KEWP, Beemer FA, Den Otter W. Non-ocular cancer in patients with hereditary retinoblastoma and their relatives. Int 7 Cancer 1988;41:499-504.

39 Imhof SM, Moll AC, Hofman P, Mourits M Ph, Schipper J, Tan KEWP. Second primary tumors in patients treated with megavoltage external beam irradiation for retinoblastoma. (Submitted for publication) 